\title{
Hubungan Calving Interval terhadap Skor BCS dan Umur Pertama Dikawinkan Sapi PO di Kecamatan Tanjung Sari
}

\author{
Kunaifi Wicaksana ${ }^{1 *}$, Dani Nur Arifin ${ }^{1}$ \\ ${ }^{1}$ Departemen Peternakan, Fakultas Peternakan, Universitas Tulang Bawang \\ *Corresponding author: kunaifi.wicaksana@gmail.com
}

\begin{abstract}
Abstrak
Calving interval $(\mathrm{CI})$ atau jarak beranak merupakan salah satu parameter untuk melihat kinerja reproduksi sapi PO. Adapun yang dapat memengaruhi calving interval diantaranya skor BCS dan umur pertama dikawinkan. Tujuan dari penelitian ini untuk menganalisis hubungan antara CI dengan skor BCS dan umur pertama dikawinkan agar dapat menjadi bahan untuk perbaikan sistem pembibitan sapi PO. Metode yang digunakan dalam penelitian ini adalah survei terhadap peternak menggunakan kuisioner. Analisis data yang digunakan dalam penelitian ini adalah deskriptif, regresi, dan korelasi dengan aplikasi Minitab 16. Berdasarkan hasil penelitian CI sapi PO adalah $14,03 \pm 3,90$ tergolong tidak ideal karena lebih dari 12 bulan. Skor BSC dan umur pertama dikawinkan berpengaruh sangat signifikan $(\mathrm{P}<0,01)$ terhadap $\mathrm{CI}$ berdasarkan analisis regresi. Skor BCS berasosiasi positif, artinya semakin tinggi skor BCS maka semakin lama CI. Umur pertama dikawinkan berasosiasi negatif dengan CI, artinya semakin tinggi nilai umur pertama dikawinkan semakin pendek CI. Bentuk hubungan CI dengan skor BCS dan umur pertama dikawinkan berdasarkan nilai R-sq masing-masing adalah 35,02\% dan 43,56\%. Tingkat keeratan hubungan CI dengan skor BCS dan umur pertama dikawinkan tergolong sedang berdasarkan nilai $\mathrm{r}$ masingmasing adalah 0,59 dan -0,66. Berdasarkan hasil penelitian diatas, dapat ditarik kesimpulan bahwa skor BCS dan umur pertama dikawinkan berpengaruh sangat signifikan terhadap CI, berasosiasi positif-negatif, dengan tingkat keeratan hubungan tergolong sedang.
\end{abstract}

Kata kunci: Calving interval, Skor BCS, Umur pertama dikawinkan, Sapi PO

\begin{abstract}
Calving Interval $(\mathrm{CI})$ or birth spacing is one of the parameters to see PO cattle reproductive performance. The calving interval that can affect them BCS score and age oft first mated. The aim of the research is to analyze the relationship between BCS and CI to score first mated age in order to be material to repair PO breeding system. The method used in this study is a survey of farmers using a questionnaire. Analysis of the data used in this research is descriptive, regression, and correlation with Minitab 16 application. Based on the results CI PO cow was $14.03 \pm 3.90$, classified as not ideal for more than 12 months. $B S C$ score and age at first mated very significant effect $(P<0,01)$ to $C I$ based on regression analysis. BCS score positive association, meaning that the higher the score the BCS then the longer CI. Age of first mated negative association with CI, meaning that the higher the value the shorter the life of the first mated CI. Forms CI relationship with BCS score and age at first mated based on the value of $R$-sq, respectively $35.02 \%$ and $43.56 \%$. The level of the relationship with the CI BCS score and age at first mated classified as moderate based on the value of $r$, respectively 0.59 and -0.66 . Based on the above results, it can be deduced that the BCS score and age at first mated very significant influence on CI, positivenegative association, with the level of closeness of relationship moderate.
\end{abstract}

Keywords: Calving interval, BCS score, Age of first mated, PO Cattle 
Prosiding Seminar Nasional Pembangunan dan Pendidikan Vokasi Pertanian Politeknik Pembangunan Pertanian Manokwari, 14 November 2020

e ISSN : 2774-1982

\section{PENDAHULUAN}

Provinsi Lampung merupakan daerah yang memiliki potensi untuk pengembangan usaha peternakan. Hal ini didukung oleh letak strategis Provinsi Lampung yang merupakan pintu gerbang transportasi utama antara Pulau Sumatera dan Jawa yang sangat potensial sebagai jalur pemasaran produk peternakan. Selain itu, Provinsi Lampung juga memiliki berbagai macam sumber daya alam yang dapat menunjang keberhasilan usaha peternakan.

Berdasarkan Surat Keputusan Bupati Lampung Selatan Nomor: B/54/III.10/HK/2011 45 tanggal 18 Februari 2011, Kecamatan Tanjung Sari ditetapkan sebagai wilayah sumber bibit/kawasan pusat pelestarian dan pengembangan sapi PO di Kabupaten Lampung Selatan. Program ini diharapkan bukan saja untuk meningkatkan populasi dan mutu genetik sapi PO, tetapi juga dapat berperan penting dalam mendukung program nasional swasembada daging sapi/kerbau yang berkelanjutan dan mampu meningkatkan pendapatan serta kesejahteraan para peternak. Diharapkan dalam jangka waktu 5 tahun kedepan wilayah Lampung Selatan dapat mewujudkan harapannya menjadikan wilayah sumber bibit Sapi PO dan Kecamatan Tanjung Sari berperan sebagai pusat pertumbuhannya sekaligus sebagai show window dan representasi keberhasilan pembangunan peternakan nasional.

Sapi PO merupakan sapi hasil persilangan antara pejantan Sapi Sumba Ongole (SO) dengan sapi betina Jawa yang berwarna putih. Saat ini sapi PO yang murni mulai sulit ditemukan, karena telah banyak disilangkan dengan sapi Brahman dan sapi eksotik lainnya, sehingga sapi PO sering diartikan sebagai Sapi Lokal/ Sapi Jawa/ Sapi Putih. Sapi PO sudah banyak dikenal oleh masyarakat, karena sebaran populasinya tersebar di seluruh wilayah Indonesia (Astuti, 2004).

Calving interval (CI) atau jarak beranak merupakan salah satu parameter untuk melihat kinerja reproduksi sapi PO. Adapun yang dapat memengaruhi calving interval diantaranya skor BCS dan umur pertama dikawinkan. Hal ini sejalan dengan pendapat Budiawan (2015) bahwa Body Condition Score memiliki hubungan dengan reproduksi ternak seperti kesuburan, kebuntingan, proses kelahiran, laktasi, semua akan mempengaruhi sistem reproduksi. Berbagai kelompok hewan bentuk tubuh (ukuran), usia, jenis kelamin, dan keturunan juga akan memiliki pengaruh yang kuat pada sistem reproduksi. Apabila ternak memiliki bobot badan yang melebihi bobot badan ideal, ternak tersebut akan mengalami gangguan reproduksi dan penyakit metabolisme, sebaliknya apabila ternak memiliki bobot badan kurang dari ideal akan berdampak pada sistem reproduksi. Menurut Desinawati dan Isnaini (2010) penampilan reproduksi dari suatu 
Prosiding Seminar Nasional Pembangunan dan Pendidikan Vokasi Pertanian Politeknik Pembangunan Pertanian Manokwari, 14 November 2020

e ISSN : 2774-1982

kelompok ternak dapat diukur dengan menggunakan beberapa parameter, diantaranya adalah system perkawinan, umur pertama dikawinkan, umur penyapihan pedet, service/conception (S/C), umur pertama beranak, jarak antara dua kelahiran dan panen pedet per tahun.

Berdasarkan uraian diatas peneliti merasa perlu untuk menganalsisis hubungan antara CI dengan skor BCS dan umur pertama dikawinkan agar dapat diketahui seberapa besar keeratan dan bentuk hubungan antar variabel sehingga dapat menjadi bahan pertimbangan dalam perbaikan sistem pembibitan sapi PO yang dilakukan oleh peternak demi tercapainya efisiensi reproduksi dan keberlanjutan usaha pembibitan sapi PO.

\section{METODE}

Penelitian ini berjenis kuantitatif yang dilaksanakan di Desa Purwodadi Kecamatan Tanjung Sari, Kabupaten Lampung Selatan pada Maret - April 2020. Objek yang digunakan pada penelitian ini berupa sapi Peranakan Ongole (PO) milik peternak yang telah di Inseminasi Buatan (IB) dan minimal dua kali beranak. Jumlah sapi PO yang digunakan 55 ekor milik 34 peternak dan data sekunder hasil dari recording peternak. Metode penelitian yang digunakan yaitu metode survei dengan cara pengambilan sampel total (sapi PO yang di IB) berupa pengamatan dan wawancara pada peternak serta catatan milik inseminator.

Variabel dependent yang digunakan dalam penelitian ini adalah nilai Calving Interval (CI). Variabel independent untuk ternak adalah skor kondisi tubuh (BCS) dan umur pertama dikawinkan. Analisis data yang digunakan diantaranya analisis deskriptif untuk mendeskripsikan hasil penelitian (Walpole, 1992), analisis regresi untuk mengetahui bentuk hubungan antara dua variabel menggunakan aplikasi MINITAB 16 (Steel dan Torrie, 1997), dan analisis korelasi untuk mengetahui tingkat keeratan hubungan antara dua variabel (Walpole, 1992). Adapun bentuk interpretasi korelasi dapat dilihat pada Tabel 1.

Tabel 1. Interpretasi korelasi

\begin{tabular}{cl}
\hline Besar xy & \multicolumn{1}{c}{ Interpretasi } \\
$0.00-<0.20$ & Hubungan antar variabel sangat rendah \\
$\geq 0.20-<0.40$ & Hubungan antar variabel rendah \\
$\geq 0.40-<0.70$ & Hubungan antar variabel sedang/ cukup \\
$\geq 0.70-<0.90$ & Hubungan antar variabel kuat/ tinggi \\
$\geq 0.90-\leq 1.00$ & Hubungan antar variabel sangat kuat/ tinggi \\
\hline
\end{tabular}

Sumber: Guilford (1956), diacu dalam Somantri dan Sambas (2006). 
Prosiding Seminar Nasional Pembangunan dan Pendidikan Vokasi Pertanian Politeknik Pembangunan Pertanian Manokwari, 14 November 2020

e ISSN : 2774-1982

\section{HASIL DAN PEMBAHASAN}

\section{Gambaran Umum Peternakan Sapi PO di Kecamatan Tanjung Sari}

Berdasarkan pengamatan di lapangan tingkat pendidikan peternak bervariasi mulai dari lulusan SD berjumlah 16 orang (47,06\%), SMP 7 orang (20,59\%), dan SMA 11 orang $(32,35 \%)$. Peternak yang memelihara sapi sebagai tabungan sebanyak 13 orang $(38,24 \%)$ dan sebagai usaha sampingan sebanyak 21 orang (61,76\%); dengan Peternak dengan lama beternak dibawah 10 tahun sebanyak 21 orang sedangkan yang diatas 10 tahun sebanyak 13 orang dengan kisaran rata-rata 11,1 $\pm 10,78$ tahun.

Pada aspek ternak semua peternak melakukan pemeriksaan kebuntingan (100\%). Ternak yang mengalami gangguan reproduksi sebanyak 11 ekor $(20,59 \%)$ sedangkan yang bebas gangguan reproduksi sebanyak 44 ekor (79,41\%). tahun. Umur penyapihan pedet 1 tahun sebanyak $(17,6 \%)$ sedangkan penyapihan pedet dibawah 1 tahun sebanyak $(82,4 \%)$ dengan kisaran rata-rata $0,8 \pm 0,13$ bulan.

\section{Hubungan Calving Interval (CI) terhadap Skor BCS dan Umur Pertama Dikawinkan}

Calving Interval adalah jarak antara kelahiran satu dengan kelahiran berikutnya pada ternak betina (Yulyanto, 2014). Tabel 2 menunjukkan Calving Interval (CI) sapi PO di Desa Purwodadi Kecamatan Tanjung Sari adalah 14,03 \pm 3,90 mengartikan efisiensi reproduksi kurang baik karena jarak beranak yang tidak ideal yakni lebih dari 12 bulan. Menurut Hardjopranjoto (1995) efisiensi reproduksi sapi dianggap baik apabila jarak antar kelahiran tidak melebihi 12 bulan. Akan tetapi lebih pendek menurut Yulyanto et al (2014) yakni $15,04 \pm 0,64$ bulan.

Tabel 2 Regresi dan korelasi CI dengan Skor BCS dan Umur Pertama Dikawinkan

\begin{tabular}{lcccc}
\hline Calving Interval (CI) & r & R-sq & R-eq & $\begin{array}{c}\text { Nilai CI } \\
\text { (bulan) }\end{array}$ \\
\hline Skor BCS $^{\text {a }}$ & 0,59 & $35,02 \%$ & $2,63+3,990$ & \\
Umur pertama dikawinkan $^{\text {a }}$ & $-0,66$ & $43,56 \%$ & $25,03-4,495$ & $14,03 \pm 3,90$ \\
\hline
\end{tabular}

Ket: superscript 'a' artinya pengaruh variabel sangat nyata (P: $<0,01)$ terhadap CI; r: korelasi; R-sq: R square (regresi); R-eq: R equivation (persamaan regresi).

BCS adalah metode pemberian scor atau nilai (1-5) terhadap tubuh seekor ternak melalui teknik penglihatan dan perabaan untuk melakukan pendugaan terhadap simpanan/cadangan lemak tubuh ternak tersebut. Semakin mendekati 5 semakin gemuk ternak tersebut (Cakra, 2012). Hasil analisis regresi skor BCS berpengaruh sangat nyata terhadap CI berdasarkan nilai $\mathrm{P}$-value $=0,000$. Nilai R-eq= 3,990 artinya bentuk hubungan antara CI dengan Skor BCS berasosiasi positif. Arti lainnya setiap pertambahan satu satuan 
Prosiding Seminar Nasional Pembangunan dan Pendidikan Vokasi Pertanian

Politeknik Pembangunan Pertanian Manokwari, 14 November 2020

e ISSN : 2774-1982

nilai skor BCS akan menambah nilai CI sebanyak 3,990. Semakin gemuk tubuh sapi PO akan memperpanjang jarak beranak.

Skor BCS di tempat penelitian yakni 2,9 $\pm 0,58$. Skor ini ideal karena tidak terlalu gemuk juga tidak terlalu kurus. Hal ini sesuai dengan pendapat Kellog (2014) bahwa penilaian BCS ternak yang ideal tergantung pada tujuan pemeliharaan. Ternak yang dipelihara dengan tujuan pembibitan tidak memerlukan kondisi tubuh yang terlalu gemuk. Pada sapi yang menderita kegemukan ada timbunan lemak yang menyebar di organ tubuh, antara lain terjadi di sekitar ovarium dan bursa ovari. Timbunan lemak ini menyebabkan folikel telur yang matang terhalang masuk ke tuba falopi dan tetap tertahan pada ovarium, sehingga tidak terjadi pembuahan. Hal ini sesuai dengan pendapat Santosa (2009), kegemukan karena pemberian pakan yang berlebihan juga akan mengganggu proses reproduksi pada ternak. Pada ternak betina, ovarium sering mengalami infiltrasi jaringan lemak sehingga dapat mencegah pertumbuhan normal folikel dan pelepasan telur yang berakibat tidak teraturnya estrus serta berkurangnya fungsi ovarium. Nilai R-sq 35,02\% artinya ada faktor lain sebanyak 64,98\% yang memengaruhi nilai CI. Sedangkan nilai $\mathrm{r}=$ 0,59 artinya tingkat keeratan hubungan antara Skor BCS terhadap CI tergolong sedang.

Hasil analisis regresi umur pertama dikawinkan berpengaruh sangat nyata terhadap CI berdasarkan nilai P-value $=0,000$. Nilai $R-e q=(-4,495)$ artinya setiap pertambahan satu satuan nilai umur pertama dikawinkan akan mengurangi nilai C! sebanyak 4,495. Arti lainnya semakin matang umur pertama dikawinkan maka akan mempersingkat jarak kebuntingan (Hasbullah, 2003).

Umur pertama dikawinkan di tempat penelitian yakni 2,4 $\pm 0,57$ tahun tergolong ideal. Hal ini sesuai dengan pendapat Sudarmono dan Sugeng (2008) bahwa sapi di Indonesia (daerah tropis) sebaiknya dikawinkan pada umur 2-2,5 tahun sebab bangsa sapi tropis tergolong lambat dewasa. Nilai R-sq 43,56\% artinya ada faktor lain sebanyak 56,44\% yang memengaruhi nilai CI. Sedangkan nilai $r=-0,66$ artinya tingkat keeratan hubungan antara umur pertama dikawinkan terhadap CI tergolong sedang.

\section{KESIMPULAN DAN SARAN}

Berdasarkan hasil penelitian diatas, dapat ditarik kesimpulan bahwa skor BCS dan umur pertama dikawinkan berpengaruh sangat signifikan terhadap CI, berasosiasi positif-negatif, dengan tingkat keeratan hubungan tergolong sedang. 


\section{DAFTAR PUSTAKA}

Astuti, M. (2004). Potensi Dan Keragaman Sumberdaya Genetik Sapi Peranakan Ongole (PO). Lokakarya Nasional Sapi Potong 2004. Fakultas Peternakan. Universitas Gadjah Mada. Yogyakarta.

Budiawan, A., Nur, I. M., \& Wahjuningsih, S. (2015). Hubungan Body Condition Score Terhadap Service per Conception dan Calving Interval Sapi Potong Peranakan Ongole di Kecamatan Babat Kabupaten Lamongan. Jurnal Ternak Tropika, Vol. 16, No. $1: 34-40,2015$.

Cakra, I. G. L. O. (2012). Teknis Penentuan Bcs Pada Ternak Sapi. Unit Sistem Informasi. Fakultas Peternakan Udayana Denpasar. https://simdos.unud.ac.id/uploads/file_penunjang_dir/2d71634d632e81f1374b5bf $\underline{8 \mathrm{df} 35 \mathrm{e} 323 . p d f}$

Desinawati, N. \& Isnaini, N. (2010). Penampilan reproduksi sapi peranakan simmental di kabupaten tulungagung jawa timur. Journal of Tropical Animal Production, 11(2), 41-47.

Hardjopranjoto. (1995). Ilmu Kemajiran Ternak. Universitas Airlangga Press. Surabaya.

Hasbullah, E.J. (2003). Kinerja Pertumbuhan dan Reproduksi Sapi Persilangan Simmental dengan Peranakan Ongole dan Sapi Peranakan Ongole di Kabupaten Bantul, Daerah Istimewa Yogyakarta. Thesis. Program Pascasarjana Fakultas Peternakan Universitas Gadjah Mada. Yogyakarta.

Kellogg, W. (2014). Body Condition Scoring with Dairy Cattles. Agriculture and Natural Resources. Division of Agriculture. The University of Arkansas. https://www.uaex.edu/publications/PDF/FSA-4008.pdf.

Santosa, U. (2009). Tata Laksana Pemeliharaan Ternak Sapi. Penebar Swadaya. Jakarta

Somantri A, \& Sambas A. (2006). Aplikasi Statistika Dalam Penelitian. Bandung (ID): CV Pustaka Setia.

Steel, R. G. D., \& Torrie, J. H. DA Dicey (1997). Principles and procedures of statistics: A biometrical approach. McGraw-Hill Co. Inc, New York NY.

Walpole, RE. (1992). Pengantar Statistika.Jakarta (ID): PT Gramedia.

Yulyanto, C. A., Susilawati, T., \& Ihsan M. N. (2014). Penampilan reproduksi sapi Peranakan Ongole (PO) dan Sapi Peranakan Limousin di Kecamatan Sawoo Kabupaten Ponorogo dan Kecamatan Tugu Kabupaten Trenggalek. Fakultas Peternakan Universitas Brawijaya. Malang. 